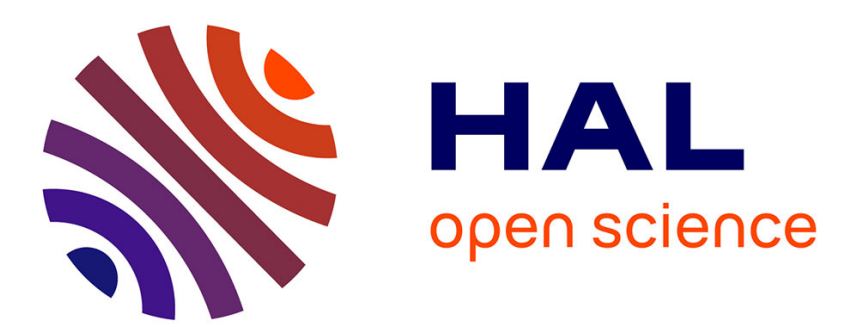

\title{
Affinity and Distribution of Silver Nanoparticles Within Plasma Polymer Matrices
}

\author{
Ali Mansour, Fabienne Poncin-Epaillard, Dominique Debarnot
}

\section{To cite this version:}

Ali Mansour, Fabienne Poncin-Epaillard, Dominique Debarnot. Affinity and Distribution of Silver Nanoparticles Within Plasma Polymer Matrices. Journal of Materials Science, 2019, 54 (19), pp.1297212987. 10.1007/s10853-019-03772-6 . hal-03016391

\section{HAL Id: hal-03016391 \\ https://hal.science/hal-03016391}

Submitted on 20 Nov 2020

HAL is a multi-disciplinary open access archive for the deposit and dissemination of scientific research documents, whether they are published or not. The documents may come from teaching and research institutions in France or abroad, or from public or private research centers.
L'archive ouverte pluridisciplinaire HAL, est destinée au dépôt et à la diffusion de documents scientifiques de niveau recherche, publiés ou non, émanant des établissements d'enseignement et de recherche français ou étrangers, des laboratoires publics ou privés. 


\title{
Affinity and Distribution of Silver Nanoparticles
}

\section{Within Plasma Polymer Matrices}

\begin{abstract}
A. Mansour, F. Poncin-Epaillard, D. Debarnot*
Institut des Molécules et Matériaux du Mans (IMMM) - UMR 6283 CNRS, Le Mans Université, Avenue Olivier Messiaen, 72085 Le Mans Cedex 9, France

*Corresponding author: Dominique.Debarnot@univ-lemans.fr

J. Mat. Sci., 54(19), 12972-12987 (2019)

\section{$\underline{\text { Abstract }}$}

The affinity and repartition of silver nanoparticles in different plasma polymer matrices are studied according to the polymer functional groups. The polymer layers are synthesized by plasma polymerization of allyl alcohol (AAl), aniline (ANI), or heptadecafluoro-1-decene (HDFD). The matrix is then impregnated in a metallic salt solution and a reducing one. When plasma polymerized (pp) ANI is used as matrix, a higher amount of silver nanoparticles (AgNPs) is introduced compared to the other two polymer matrices. Otherwise, with pp-AAl, smaller AgNPs with narrower size distribution are inserted. Finally, different plasma polymer/AgNPs interaction mechanisms are proposed according to the polymer functional groups. Moreover, the sensing behavior of pp-ANI, well-known as sensitive layer towards ammonia, is markedly enhanced by the presence of AgNPs.
\end{abstract}

Keywords: hybrid nanocomposites; plasma polymer; silver nanoparticles; metal distribution; polymer/metal interaction. 


\section{Introduction}

Polymer/metal nanocomposites have attracted considerable attention as they combine the advantages of both polymer and metal offering interesting properties in many fields such as electronics, photonics, sensing, catalysis, biology and medicine. ${ }^{1-5}$

Among the several approaches to elaborate such hybrid nanocomposite materials, the generation of metal nanoparticles from a metal precursor in the polymer, considered as a simple approach, is carried out by mixing the polymer with the metal precursor followed by different physical (photoirradiation, thermal treatment) or chemical treatments (chemical reduction by hydrazine, sodium citrate, or sodium borohydride). ${ }^{2,6}$ In a lot of studies, the polymer matrix is synthesized by conventional ways (chemical or electrochemical ones). ${ }^{7-10}$

Recently, plasma polymerization is gaining more and more attention for its ecofriendly process (e.g., solvent free). Indeed, plasma polymerization is initiated by collisions of the monomer molecules (many organic and inorganic vapors) with free electrons accelerated by the electric field. It results in the formation of excited species, radicals and ions. Different reactions (recombination, addition...) will then be held between these active species to form the plasma polymer leading to a more irregular structure compared to conventional polymers. However, a great resemblance to conventional polymers can be obtained after optimizing plasma parameters such as discharge power, duty-cycle, frequency, etc. A large range of polymers with various functional groups can be obtained by plasma polymerization.

Different plasma polymer/metal composite materials have been synthesized by the approach mentioned before, using n-heptylamine, ${ }^{11}$ acrylic acid, ${ }^{12}$ allyl alcohol, ${ }^{13}$ or maleic anhydride ${ }^{14}$ as monomers, silver nitrate $\left(\mathrm{AgNO}_{3}\right)$ as metallic solution, and sodium borohydride $\left(\mathrm{NaBH}_{4}\right)$ solution as silver reducing agent. The purpose of these studies concerns the antibacterial application, and no intensive investigation on the role of the polymer nature on the silver nanoparticles (AgNPs) formation was realized. However, the properties of the composites are 
highly dependent on the distribution of the metal particles in the polymer matrix. Therefore, the objective of this work is to study the silver nanoparticles formation: amount, size, size distribution and oxidation state according to the chemical composition of the polymer matrix, in order to better understand the interaction mechanisms between metal ions and the plasma polymer. For this purpose, different plasma polymer layers with different functional groups are chosen containing nitrogen, oxygen or fluorine functions using aniline (ANI), allyl alcohol (AAl) or heptadecafluoro-1-decene (HDFD) as precursors respectively. The formation of silver nanoparticles into these matrices is carried out by impregnation in $\mathrm{AgNO}_{3}$ metallic solution followed by a chemical reduction in $\mathrm{NaBH}_{4}$.

Ammonia $\left(\mathrm{NH}_{3}\right)$ sensing is one of the most attractive applications due to its large production and toxicity. ${ }^{15-17}$ Indeed, numerous studies have recently been devoted to the development of polymer-based gas sensors for $\mathrm{NH}_{3}$ detection, specially polyaniline well-known for its selectivity to ammonia. ${ }^{18-21}$ Moreover, an improved sensing performance of conventional polymers towards different toxic gases is shown by incorporating metals such as $\mathrm{Cu}, \mathrm{Ag}, \mathrm{Pt}, \mathrm{Pd}$ etc. ${ }^{22-25}$ Polyaniline/AgNPs composites have then been prepared for the detection of ammonia both in solution based on the change in color of the films ${ }^{26}$ and in gas phase based on the change of electrical or optical properties of the layers ${ }^{27,28}$. In these works, polyaniline is synthesized by conventional ways and no real investigation is carried out in order to understand how these metals could improve sensing performance. In our work, polyaniline is elaborated by the plasma technique with the purpose to demonstrate how the metal nanoparticles can improve the ammonia gas sensing. Therefore, the final part of this work concerns the study of the ammonia sensitivity, evaluated by absorbance variation, of plasma polymerized aniline (pp-ANI) containing silver nanoparticles compared to bare pp-ANI.

\section{Experimental}




\subsection{Materials and methods}

Aniline (mol. wt $=93.13 \mathrm{~g} \cdot \mathrm{mol}^{-1}$, purity $\geq 99.5 \%$, allyl alcohol $\left(\mathrm{mol} . \mathrm{wt}=58.08 \mathrm{~g} \cdot \mathrm{mol}^{-1}\right.$, purity $\geq 98.5 \%$ ), and heptadecafluoro-1-decene (mol. wt $=446.1 \mathrm{~g} \cdot \mathrm{mol}^{-1}$, purity $\left.=99 \%\right)$ monomers were obtained from Sigma-Aldrich and used as received. The structure of the monomers is given in Figure 1. Silver nitrate $\left(\mathrm{AgNO}_{3}\right)$ (mol. wt $=169.87 \mathrm{~g} \mathrm{~mol}^{-1}$, Fisher), sodium borohydride $\left(\mathrm{NaBH}_{4}\right)\left(\right.$ mol. wt $=37.83 \mathrm{~g} \mathrm{~mol}^{-1}$, purity $=96 \%$, Sigma Aldrich), and doubly distilled water (Millipore, resistivity $18 \mathrm{M} \Omega . \mathrm{cm}$ ) were used to prepare the aqueous solution of the metal salt and the reducing agent, respectively.

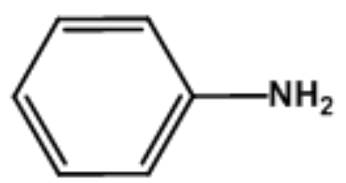

(a)

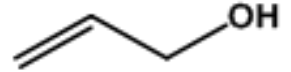

(b)

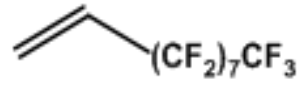

(c)

Figure 1. Chemical structures of the monomers (a) aniline, (b) allyl alcohol and (c) heptadecafluoro-1-decene.

\subsection{Incorporation of silver nanoparticles into the different plasma polymer films}

The plasma polymers' synthesis and deposition were achieved in a cylindrical aluminum reactor capacitively coupled with two parallel circular electrodes with a R.F. (13.56 MHz) generator. The adhesion of the plasma polymer layers to the different types of substrates was successfully enhanced by argon plasma pre-treatment $(P=100 \mathrm{~W}, F=10 \mathrm{sccm}, t=1 \mathrm{~min})$. The plasma polymerization of ANI, AAl and HDFD was realized in pulsed mode using plasma parameters optimized to a power $(P)$ equal to $30 \mathrm{~W}$, a duty cycle $(D . C$.) of $50 \%$ (defined as D.C. $=$ discharge time $\left(t_{o n}\right) /$ (discharge $\left(t_{o n}\right)+$ post-discharge $\left(t_{o f f}\right)$ times), and a frequency of $30 \mathrm{kHz}$. In order to avoid thickness dependence, different deposition times $(8,20$, and $5 \mathrm{~min}$, respectively for the polymerization of ANI, AAl and HDFD) were judiciously selected to obtain the same thickness 
of about $\sim 285 \pm 5 \mathrm{~nm}$. Then, all these polymers were successively dipped in $0.1 \mathrm{M} \mathrm{AgNO}_{3}$ for $3 \mathrm{~h}$ and $0.1 \mathrm{M} \mathrm{NaBH}_{4}$ aqueous solutions for $1 \mathrm{~h}$ at room temperature under continuous and constant stirring in a dark place. The concentrations and dipping times of the silver salt and the reducing agent have been optimized in a previous work. ${ }^{29}$ Between each step, the composites were rinsed with distilled water and dried with air.

\subsection{Characterization techniques}

UV-Vis spectroscopy is known to be the most used technique for metal nanoparticle characterization. UV-Vis absorption measurements were performed with Varian Cary 100, in the wavelength range of $200-900 \mathrm{~nm}$, using glass slides as substrates. The spectra were measured in a double beam mode and the reference was carried out with a glass slide.

The silicon wafers, used for determination of the layer thickness via atomic force microscopy (AFM, Bruker-Innova), were preventively cleaned and partially masked with a stable adhesive tape during the plasma deposition. AFM operating in the tapping mode was also used to examine the topography and roughness of the polymer and composite thin films. The root mean square roughness $(\mathrm{Rq})$ values were derived from $(10 \mathrm{x} 10 \mu \mathrm{m})$ AFM images using the Gwiddion software.

The metal particle size, size distribution, and metal diffraction patterns were determined by the transmission electron microscopy (TEM) micrographs coupled with selected area electron diffraction (SAED). These characterizations were carried out on a JEOL (STEM 2100) microscope operating at $200 \mathrm{kV}$. The samples must have a thickness lower than $100 \mathrm{~nm}$ and deposited on nickel grids (Formvar/carbon film, 200 mesh, Ni, USA / Canada).

The FTIR-ATR spectra were recorded in the absorbance mode in the range of $400-4000 \mathrm{~cm}^{-1}$ with a resolution of $2 \mathrm{~cm}^{-1}$ using 32 scans. The spectrometer was a Bruker-vertex $70 \mathrm{~V}$ apparatus with a globar light source and a DTGS detector. Polypropylene (PP) (Goodfellow Production, 
England) was used as substrate for the deposition of plasma polymers and plasma polymer/metal nanocomposites. All the spectra were normalized with respect to thickness. The spectra were measured in the Attenuated Total Reflectance (ATR) technique using diamond. The sampling depth was in the range of about $1.66 \mu \mathrm{m}$ at $1000 \mathrm{~cm}^{-1}$ and $45^{\circ}$ as angle of incidence.

XPS determination of surface structures deposited onto silicon wafers (100) (Neyco s.a., France) was carried out on an Axis Nova (Kratos) instrument at the Institut des Matériaux de Nantes, France. The emission was analyzed at a take-off angle of $90^{\circ}$ relative to the sample surface, yielding a sampling depth of maximal $10 \mathrm{~nm}$ due to the mean free path of the electrons. The curve fitting was performed using CasaXPS software (Casa Software Ltd.). The peak shape was chosen with Gaussian (70\%)/Lorentzian (30\%) curve fitting and quantification was reliable to $\pm 5 \%$.

\subsection{Gas sensing}

The ex-situ (out of the plasma reactor) doping with iodine has been used in this work to obtain $\mathrm{NH}_{3}$ sensitive thin films. It consists of introducing the polymer and nanocomposite films into a chamber saturated with iodine vapours $\left(\mathrm{I}_{2}\right.$, Aldrich) during $24 \mathrm{~h}$.

The optical ammonia gas sensing system (Figure 2) is composed of a sealed measuring chamber inserted into the UV-Vis spectrophotometer, a gas dilution system with flowmeters and gas cylinders, and a computer for data collection. The gas sensitive films (doped pp-ANI or doped pp-ANI/AgNPs) deposited onto glass substrates were introduced into the sealed chamber. A stream of nitrogen gas containing ammonia was then passed through the sensitive film and spectroscopic measurements were performed. The concentration of $\mathrm{NH}_{3}$ was varied by mixing different flows of $\mathrm{NH}_{3}$ and $500 \mathrm{sccm}$ of $\mathrm{N}_{2}$. The concentration of $\mathrm{NH}_{3}$ (ppm) was defined as the ratio of the flow rate of $\mathrm{NH}_{3}$ to the total flow rate of $\mathrm{NH}_{3}$ and $\mathrm{N}_{2}$. In this work, the ammonia 
concentration varied between 92 and 4618 ppm. The ammonia concentrations lower than 92 ppm were not measured due to experimental set-up limitation. The interaction between $\mathrm{NH}_{3}$ and the sensitive film leads to its optical absorbance variation. When the absorbance variation tends to a constant value depending on time, the $\mathrm{NH}_{3}$ gas was turned off and stream of pure $\mathrm{N}_{2}$ was passed through the sensor to purge completely the $\mathrm{NH}_{3}$ molecules in the measuring chamber and to regenerate the sensitive film. The wavelength of the light source used in this work was fixed at $430 \mathrm{~nm}$. All experiments were performed at room temperature. Sensitivity (S) was calculated as $\left(\mathrm{A}^{-} \mathrm{A}_{0}\right) / \mathrm{A}_{0}$ ratio, where $\mathrm{A}_{0}$ is the initial optical absorbance of the sensor under $\mathrm{N}_{2}$ and $\mathrm{A}$, the absorbance of the sensor when exposed to ammonia gas. The sensitivity value given for one concentration is the average of at least three measurements.

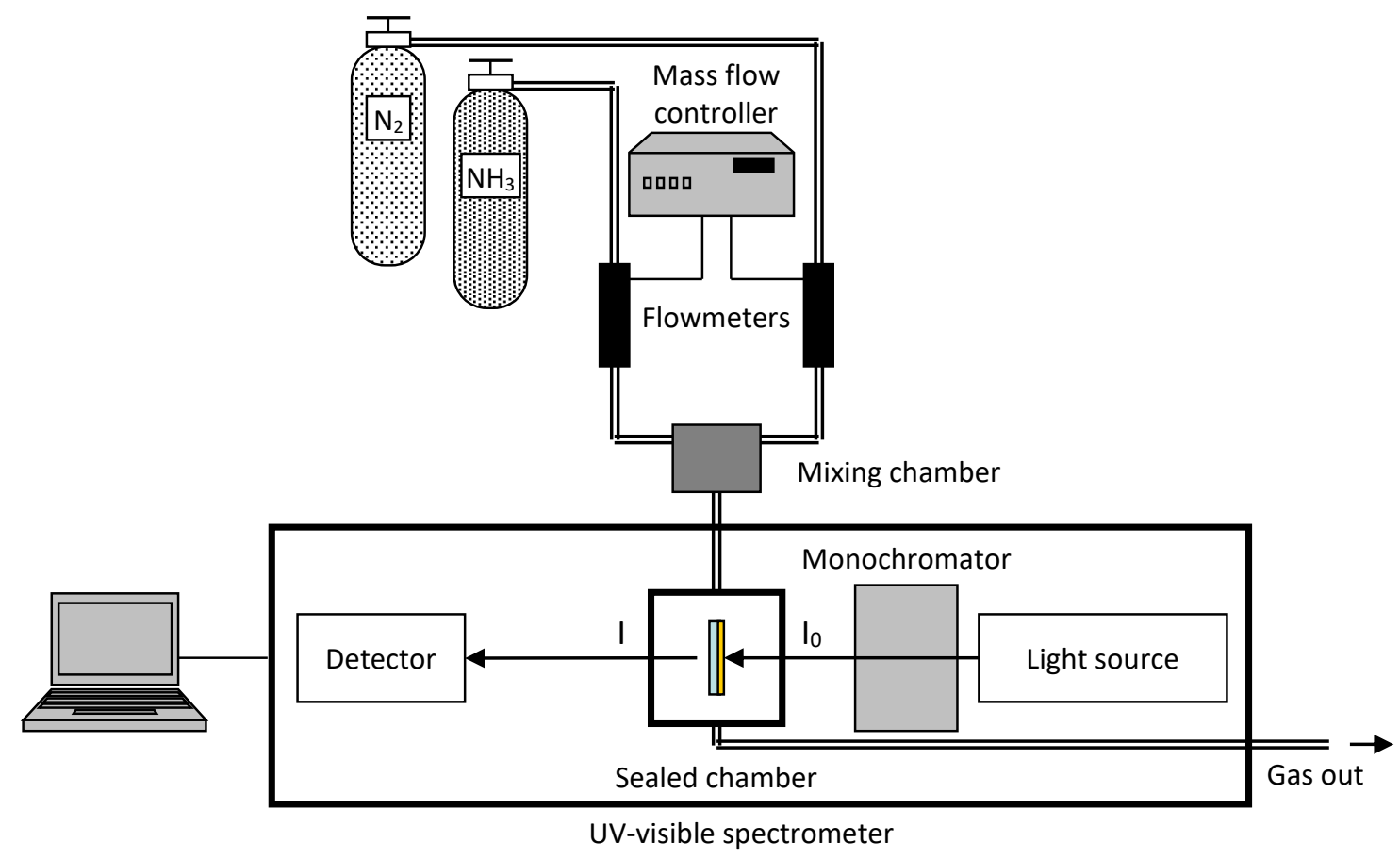

Figure 2. Experimental set-up of ammonia gas sensing based on absorbance variation measurement.

\section{Results and discussion}

In order to describe the plasma polymer/silver interaction mechanisms, the silver chemical affinities towards plasma polymers, and the polymer chemical functions involved with, are first 
investigated. In a second time, the silver particle size, and particle size distribution are examined according to the polymer matrix. We are interested in three polymer matrices with different chemical functions: pp-ANI, pp-AAl and pp-HDFD. The interest of such composite materials is finally demonstrated through the study of its gas sensitivity using pp-ANI as matrix, which is well-known to be sensitive to ammonia.

\subsection{Silver chemical affinity towards plasma polymers}

Table 1 shows the XPS quantification of the different elements in the plasma polymer and composite materials.

Table 1. XPS quantification of the different elements in the plasma polymers and nanocomposites.

\begin{tabular}{|c|c|c|c|c|c|}
\hline \multirow{2}{*}{} & \multicolumn{5}{|c|}{ Atomic percentages (\%) } \\
\cline { 2 - 6 } & $\mathrm{C}$ & $\mathrm{N}$ & $\mathrm{O}$ & $\mathrm{F}$ & $\mathrm{Ag}$ \\
\hline Bare pp-ANI & $87.1 \pm 4.3$ & $9.2 \pm 0.5$ & $3.7 \pm 0.2$ & - & - \\
\hline pp-ANI after impregnation+reduction & $82.7 \pm 4.1$ & $6.6 \pm 0.3$ & $5.8 \pm 0.3$ & - & $4.9 \pm 0.2$ \\
\hline Bare pp-AAl & $81.2 \pm 4.1$ & - & $18.8 \pm 0.9$ & - & - \\
\hline pp-AAl after impregnation+reduction & $81.1 \pm 4$ & - & $17.9 \pm 0.9$ & - & $0.9 \pm 0.04$ \\
\hline Bare pp-HDFD & $50.2 \pm 2.5$ & - & $0.4 \pm 0.02$ & $49.4 \pm 2.5$ & - \\
\hline pp-HDFD after impregnation+reduction & $52.6 \pm 2.6$ & - & $1.4 \pm 0.07$ & $45.9 \pm 2.3$ & $0.1 \pm 0.01$ \\
\hline
\end{tabular}

The presence of oxygen in plasma polymers deposited from monomers which do not contain oxygen (like ANI and HDFD) is due to the fact that the plasma polymer surfaces remain active and react with atmospheric oxygen after the films are removed from the reactor chamber. ${ }^{30-32}$ As well as, the lower experimental ratios than the theoretical ones expected from the starting monomer N/C (0.1 vs. 0.16$), \mathrm{O} / \mathrm{C}$ (0.23 vs. 0.33$)$, and F/C (1 vs. 1.7$)$ of pp-ANI, pp-AAl and 
pp-HDFD respectively are mostly ascribed to fragmentations of the monomer in the R.F. glow discharge followed by a loss of nitrogen, oxygen, and fluorine during the polymerization..$^{33,34}$ Moreover, the surface rearrangement phenomena of plasma polymers can also contribute to these theoretical and experimental differences. ${ }^{35,36}$

All the composites are shown to contain $\mathrm{Ag}, \mathrm{C}$, and $\mathrm{O}$ near their surfaces, in addition to $\mathrm{N}$ for pp-ANI matrix and F for pp-HDFD one. A decrease in nitrogen and fluorine percentages is observed for the pp-ANI and pp-HDFD composites, with at the same time, an increase in the oxygen percentage. We can suppose that nitrogen and fluorine groups move from the surface to the bulk of the polymers when dipped in the aqueous solutions. The presence of AgNPs leaves this organization fixed once the composite is formed. The increase of the $\mathrm{O}$ percentage for the pp-ANI and pp-HDFD composites may be explained by the higher reactivity of the latter for which active species are mainly diradicals, whereas monoradicals species are principally created in pp-AAl. ${ }^{37}$

The characteristic doublet at $368.6 \mathrm{eV}$ and $374.6 \mathrm{eV}$ of $\mathrm{Ag} 3 \mathrm{~d}_{5 / 2}$ and $\mathrm{Ag} 3 \mathrm{~d}_{3 / 2}$ with a difference of $6 \mathrm{eV}$ on the wide-scan XPS spectra (not shown here) indicates that silver particles have been successfully synthesized in all the composites. ${ }^{13,38}$ However, the amount of silver depends on the type of the polymer matrix, since pp-ANI shows the most significant amount of silver (4.9\%), then pp-AAl $(0.9 \%)$ and pp-HDFD $(0.1 \%)$. One of the main reasons for this difference is the type of interaction that exists between the polymer functional groups and the metal ions. In order to identify which chemical functions are involved through plasma polymer/silver interactions, XPS studies of N1s, and O1s are presented in Table 2.

Table 2. Atomic percentages of the different components in the high resolution XPS spectra of (a) N1s of pp-ANI, and (b) O1s of pp-AAl after impregnation+reduction. 


\begin{tabular}{|c|c|c|c|c|c|}
\hline & $\begin{array}{c}-\mathrm{N}= \\
(398.7 \pm 0.2 \mathrm{eV})\end{array}$ & $\begin{array}{c}-\mathrm{NH}- \\
(399.7 \mathrm{eV})\end{array}$ & $\begin{array}{c}\stackrel{+\bullet}{\mathrm{NH}}- \\
(400.6 \mathrm{eV})\end{array}$ & $-\mathrm{NH}-/-\mathrm{N}=$ & $-\stackrel{+\bullet}{\mathrm{NH}}-/-\mathrm{N}=$ \\
\hline $\begin{array}{c}\text { Bare pp-ANI } \\
(\text { fwhm }=1.4 \mathrm{eV})\end{array}$ & $6.2 \pm 0.3$ & $82.7 \pm 4.1$ & $11 \pm 0.5$ & $13.3 \pm 1.3$ & $1.8 \pm 0.2$ \\
\hline $\begin{array}{c}\text { pp-ANI after impregnation } \\
\quad(\text { fwhm }=1.3 \mathrm{eV})\end{array}$ & $6.8 \pm 0.3$ & $76.9 \pm 3.8$ & $16.3 \pm 0.8$ & $11.3 \pm 1.1$ & $2.4 \pm 0.2$ \\
\hline $\begin{array}{c}\text { pp-ANI after } \\
\text { impregnation+reduction } \\
(\text { fwhm }=1.4 \mathrm{eV})\end{array}$ & $4.4 \pm 0.2$ & $80.5 \pm 4$ & $15.1 \pm 0.7$ & $18.2 \pm 1.8$ & $3.4 \pm 0.3$ \\
\hline
\end{tabular}

(a)

\begin{tabular}{|c|c|c|}
\hline & $\begin{array}{c}\mathrm{C}-\underline{\mathrm{O}} \mathrm{H} / \mathrm{R}, \underline{\mathrm{O}}-\mathrm{C}-\underline{\mathrm{O}} \\
(532.8 \pm 0.1 \mathrm{eV})\end{array}$ & $\begin{array}{c}\mathrm{C}=\underline{\mathrm{O}} \\
(533.9 \pm 0.1 \mathrm{eV})\end{array}$ \\
\hline $\begin{array}{c}\text { Bare pp-AAl } \\
\text { (fwhm = 1.5 eV) }\end{array}$ & $91.4 \pm 4.6$ & $8.6 \pm 0.4$ \\
\hline $\begin{array}{c}\text { pp-AAl after impregnation } \\
\text { (fwhm = 1.8 eV) }\end{array}$ & $65.6 \pm 3.3$ & $34.4 \pm 1.7$ \\
\hline $\begin{array}{c}\text { pp-AAl after } \\
\text { impregnation+reduction } \\
(\mathbf{f w h m}=\mathbf{1 . 7} \mathbf{~ e V})\end{array}$ & $98 \pm 4.9$ & $2 \pm 0.1$ \\
\hline
\end{tabular}

(b)

Concerning pp-ANI, the N1s spectra can be decomposed into three peaks at 398.7 and 399.7 $\mathrm{eV}$, attributed to the imine $(-\mathrm{N}=)$ and amine $(-\mathrm{NH}-)$ groups of polyaniline, respectively, and at higher binding energy $(400.6 \mathrm{eV})$ due to the positively charged nitrogen groups (-NH-). ${ }^{39-42}$ The decrease of amine functions of pp-ANI after adding metallic salt indicates that this last is oxidized by the silver ions to increase the level of doping $(-\stackrel{+}{\mathrm{N}} \mathrm{H}-)$, showing that $\mathrm{Ag}^{+}$ions play the role of oxidizing dopant. The FTIR-ATR spectra (Figure 3-a) also reveal that the amines are the main chemical groups that interact with silver ions, by the decrease of the band at 3370 $\mathrm{cm}^{-1}(\mathrm{vN}-\mathrm{H})$. This result shows that the interaction of the $(-\stackrel{+\bullet}{\mathrm{NH}}-/-\mathrm{NH}-)$ redox couple of pp- 
ANI with the silver ions is favored compared to the (-N=/-NH-) one whose standard potential $\left(\mathrm{E}^{\circ}(-\mathrm{N}=/-\mathrm{NH}-)=0.7-0.75 \mathrm{~V}\right)^{43}$ is too close to that of silver ions $\left(\mathrm{E}^{\circ}\left(\mathrm{Ag}^{+} / \mathrm{Ag}\right)=0.80 \mathrm{~V}\right)^{44,45}$. To get a complete reduction of $\mathrm{Ag}^{+}$, the $\mathrm{NaBH}_{4}$ solution $\left(\mathrm{E}^{\circ}\left(\mathrm{H}_{2} \mathrm{BO}_{3}-\mathrm{BH}_{4}^{-}\right)=-1.24 \mathrm{~V}\right)$ induces not only the reduction of the remaining metallic ions but also that of pp-ANI, since we observe a decrease in the imine $(-\mathrm{N}=)$ functions and an increase in the amine ones $(-\mathrm{NH}-)$ (Table 2-a), whereas the $-\stackrel{+\bullet}{\mathrm{NH}}$ - concentration remains unchanged. The fact that $\mathrm{NaBH}_{4}$ is not able to reduce the $-\stackrel{+\bullet}{\mathrm{NH}}$ - groups into amine ones suggests that the redox standard potential of $-\stackrel{+\bullet}{\mathrm{NH}}-/-\mathrm{NH}-$, not found in the literature, is close to that of $\mathrm{NaBH}_{4}$. The standard potentials of pp-ANI, silver and $\mathrm{NaBH}_{4}$ are summarized in Table 3-a.

Regarding pp-AAl, the polymer chain of pp-AAl is also oxidized by silver ions, as shown by the $\mathrm{O} 1 \mathrm{~s}$ decomposition ${ }^{46}$ where a remarkable decrease of $\mathrm{C}-\underline{\mathrm{O}} \mathrm{H} / \mathrm{R}, \underline{\mathrm{O}}-\mathrm{C}-\underline{\mathrm{O}}$, with an increase of $\mathrm{C}=\underline{\mathrm{O}}$ is observed (Table 2-b). This result is also well observed on the FTIR-ATR spectra of pp$\mathrm{AAl}$ (Figure 3-b), by the decrease of the characteristic band at $3380 \mathrm{~cm}^{-1}$ assigned to $\mathrm{vOH}$, and which indicates the interaction between $\mathrm{OH}$ functions and $\mathrm{Ag}^{+}$. Thereafter, to get a complete reduction of $\mathrm{Ag}^{+}$, the $\mathrm{NaBH}_{4}$ solution induces also the reduction of pp-AAl where an important increase of the hydroxyl functions is observed after reduction (Table 2-b and Figure 3-b). All these results are consistent with the standard potentials of pp-AAl $\left(\mathrm{E}^{\circ}(\mathrm{C}=\mathrm{O} / \mathrm{C}-\mathrm{O})=-0.16 \mathrm{~V}\right)^{47}$, silver and $\mathrm{NaBH}_{4}$ which are summarized in Table 3-b. 


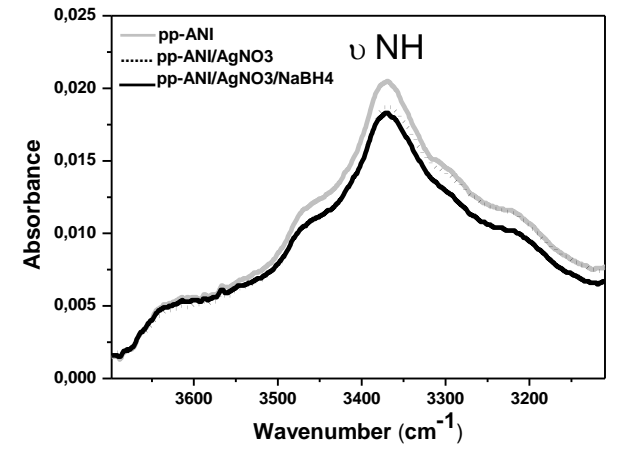

(a)

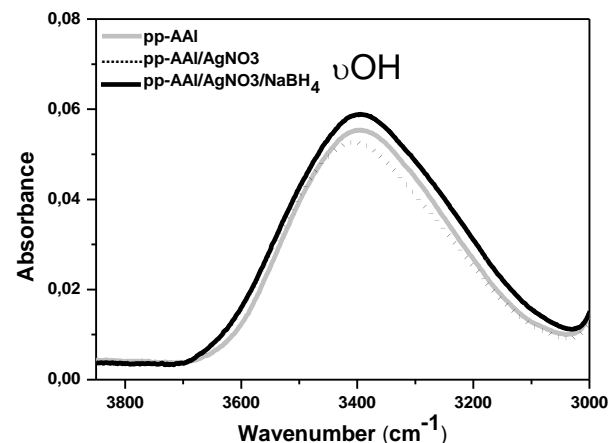

(b)

Figure 3. FTIR-ATR spectra of (a) pp-ANI, and (b) pp-AAl after impregnation+reduction.

Table 3. Redox standard potentials of (a) pp-ANI and (b) pp-AAl with those of silver and the reducing agent.

\begin{tabular}{|c|c|c|c|}
\hline & $\mathbf{E}^{\circ}(\mathbf{V})$ & & $\mathbf{E}^{\circ}(\mathbf{V})$ \\
\hline $\mathrm{Ag}^{+} / \mathrm{Ag}$ & 0.80 & $\mathrm{Ag}^{+} / \mathbf{A g}$ & 0.80 \\
\hline pp-ANI (-N=/-NH-) & $0.70-0.75$ & pp-AAl $(C=O / C-O)$ & -0.16 \\
\hline pp-ANI ( - $\stackrel{+\bullet}{\text { NH }}-/-\mathbf{N H}-)$ & $<-1.00$ & $\mathrm{H}_{2} \mathrm{BO}_{3}^{-} / \mathrm{BH}_{4}^{-}$ & -1.24 \\
\hline $\mathrm{H}_{2} \mathrm{BO}_{3}^{-} / \mathrm{BH}_{4}^{-}$ & -1.24 & & \\
\hline
\end{tabular}

(a)

(b)

The oxidation of the polymer chains of pp-ANI and pp-AAl after impregnation in the metallic salt solution, must therefore be accompanied by a reduction of $\mathrm{Ag}^{+}$ions. For pp-ANI (Figure 4-a,b) and pp-AAl (Figure 4-c,d) matrices containing silver, the Ag 3d5/2 peak envelop is decomposed into two component peaks at $366.9 \mathrm{eV}$ and $368.9 \mathrm{eV}$, which correspond to two different oxidation states of silver, namely silver oxide $\left(\mathrm{Ag}^{+\mathrm{I}}\right)$ and metallic silver $\left(\mathrm{Ag}^{\circ}\right)$, respectively. It is known that a metal ion having a higher standard potential than a polymer, once in contact, can be spontaneously reduced by this last to form zero-valent metal. This is the 
case of pp-ANI used as a polymeric matrix and as silver reducing agent. The incomplete reduction even after adding $\mathrm{NaBH}_{4}$, may be explained by the strong interaction between $\mathrm{Ag}^{+}$ and nitrogen functions, and the possible formation of a complex as shown by XPS (Figure 4a,b). It has already been reported the formation of coordination bonds of nitrogen-containing polymers such as polyaniline,${ }^{48}$ poly(1,8-diaminonaphthalene) ${ }^{49}$ polyacrylonitrile ${ }^{50}$ with silver ions due to the nitrogen free electron pair that interacts with the metal ions.

Based on the standard potential of pp-AAl, $\mathrm{Ag}^{+}$is reduced to its metallic form $\left(97.2 \% \mathrm{of}^{\circ}\right.$ ) by the latter (Figure 4-c,d). In fact, the use of alcohols as reducing agents is well-known in the literature. ${ }^{51}$ In contrast to pp-ANI, no silver ions are observed after reduction, and all the remaining $\mathrm{Ag}^{+}$ions are converted to $\mathrm{Ag}^{\circ}$ by $\mathrm{NaBH}_{4}$ which is a stronger reducing agent (lower standard potential) than the polymer matrix. Therefore, the only type of interaction between $\mathrm{Ag}^{+}$and $\mathrm{OH}$ functions is the electrostatic one.

It has been shown in the literature, a decrease of the free electrons pair ability to form a coordinating bond with a metal, when the electronegativity of atoms increases. ${ }^{52,53}$ The electron donating ability of nitrogen in pp-ANI is then higher than that of oxygen in pp-AAl since the electronegativity of nitrogen is lower than that of oxygen. Additionally, the pp-ANI structure is rich in $\pi$ electrons (aromaticity) which further promotes the coordination between $\mathrm{Ag}^{+}$and $\mathrm{N}$ atoms, thus explaining this higher affinity of $\mathrm{Ag}^{+}$towards pp-ANI (4.9\% of $\mathrm{Ag}$ ) compared to pp-AAl $(0.9 \%$ of $\mathrm{Ag})$.

For pp-HDFD (Figure 4-e,f), the Ag3d $\mathrm{d}_{5 / 2}$ high resolution XPS spectra decomposition shows that silver is present in its metallic state. Due to the weak interaction between silver ions and the fluorine components $(0.1 \% \mathrm{Ag})$, it can be predicted that the oxygen functions present in a very small quantity $(0.4 \%)$ could interact with the silver ions and reduce them.

Therefore, the plasma polymers play the role of reducing agents, contributing to the formation of metallic particles. 


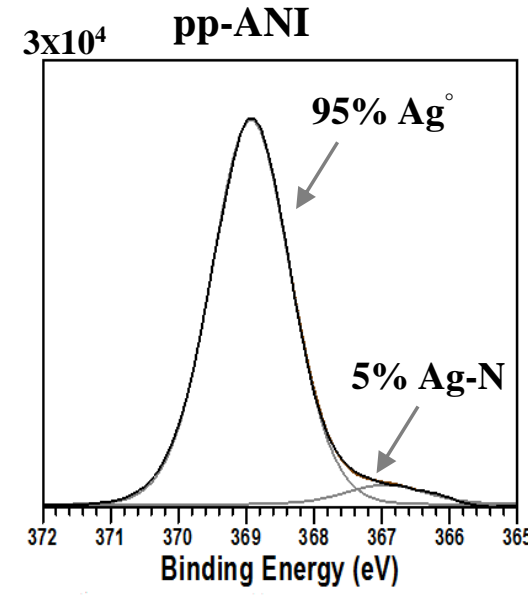

(a)

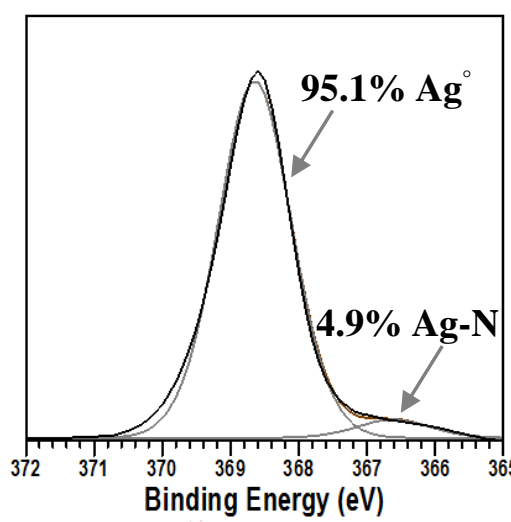

(b)

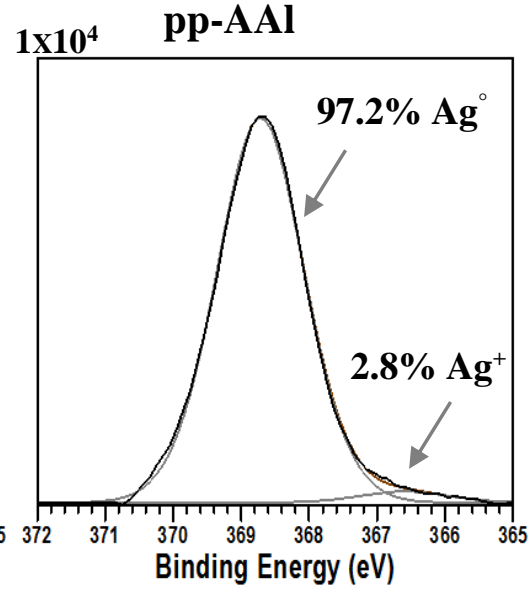

(c)

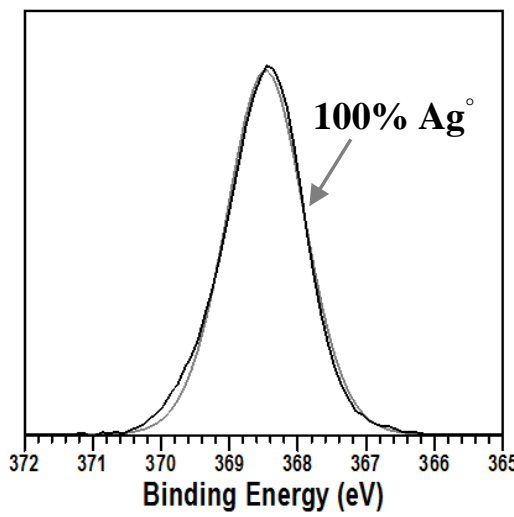

(d)

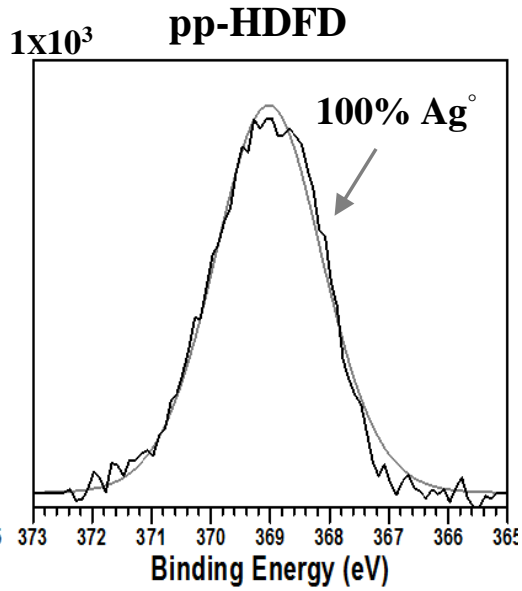

(e)

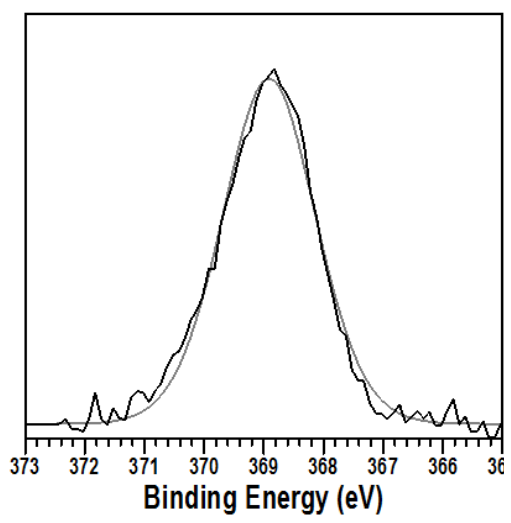

(f)

Figure 4. Ag 3d $\mathrm{d}_{5 / 2}$ high resolution XPS spectra of (a) pp-ANI, (c) pp-AAl, (e) pp-HDFD after impregnation, and (b) pp-ANI, (d) pp-AAl, (f) pp-HDFD after impregnation+reduction.

Following these results, the proposed interaction mechanism between pp-ANI and silver salt on the one hand, and the reducing agent on the other hand is presented in scheme 1, according to the results observed by FTIR-ATR and XPS. The chemical structure of pp-ANI is non-linear due to the fragmentation and the recombination of the monomer in the plasma phase. This fragmentation can give rise to a loss of aromaticity either by the aromatic ring opening or by the $\pi$-bond scission in the aromatic ring. pp-ANI mainly contains amine functions, with some 
imines and positively charged nitrogen groups, in addition to oxygen functions following the post-oxidation of the polymer.

There are two different reactions that occur during the pp-ANI/AgNPs formation. One of them is the electrostatic interaction between $\mathrm{Ag}^{+}$and $\mathrm{pp}-\mathrm{ANI}$ followed by the reduction of $\mathrm{Ag}^{+}$ leading to the metallic nanoparticles $\mathrm{Ag}^{\circ}$, where at the same time, pp-ANI is oxidized (increase of $-\stackrel{+\bullet}{\mathrm{NH}}-)$. The other one is the complexation of $\mathrm{Ag}^{+}$with the amine groups. Thus, the interactions are of electrostatic and coordination type,${ }^{54}$ taking into consideration that the electrostatic interaction followed by the reduction is more predominant than that of the complexation. After reduction, the imines functions are reduced by the $\mathrm{NaBH}_{4}$ solution into amines.

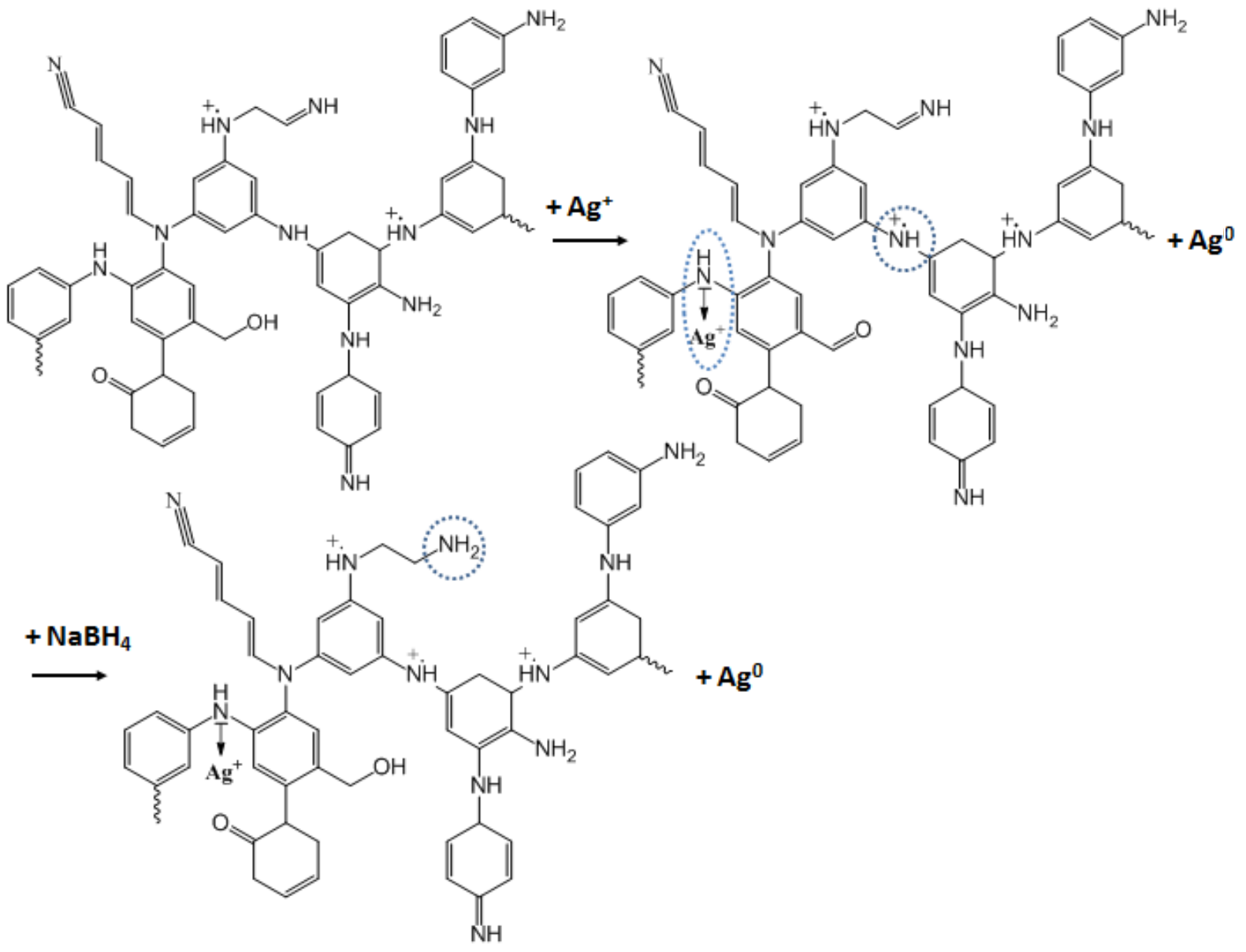

Scheme 1. Complexation and electrostatic interactions between $\mathrm{Ag}^{+}$and pp-ANI. 
Concerning pp-AAl, its chemical structure is also non-linear due to the fragmentation and the recombination of the monomer in the plasma phase. pp-AAl mainly contains hydroxyl functions, with some carbonyl and carboxyl groups.

The mechanism that can be involved in the formation of $\mathrm{Ag}^{\circ}$ in the $\mathrm{pp}-\mathrm{AAl}$ matrix is presented in scheme 2, where only the electrostatic interaction mechanism is involved in the nanocomposite formation, followed by the reduction of $\mathrm{Ag}^{+}$. At the same time, hydroxyl groups of pp-AAl are oxidized to form $-\mathrm{C}=\mathrm{O}$ groups corresponding either to a ketone, an aldehyde or a carboxyl group. After reduction, the $-\mathrm{C}=\mathrm{O}$ groups are reduced to hydroxyl ones, and a new bond is formed $\left(\mathrm{COO}^{-} \mathrm{Na}^{+}\right)$as a result of the interaction of pp-AAl with the $\mathrm{NaBH}_{4}$ solution.

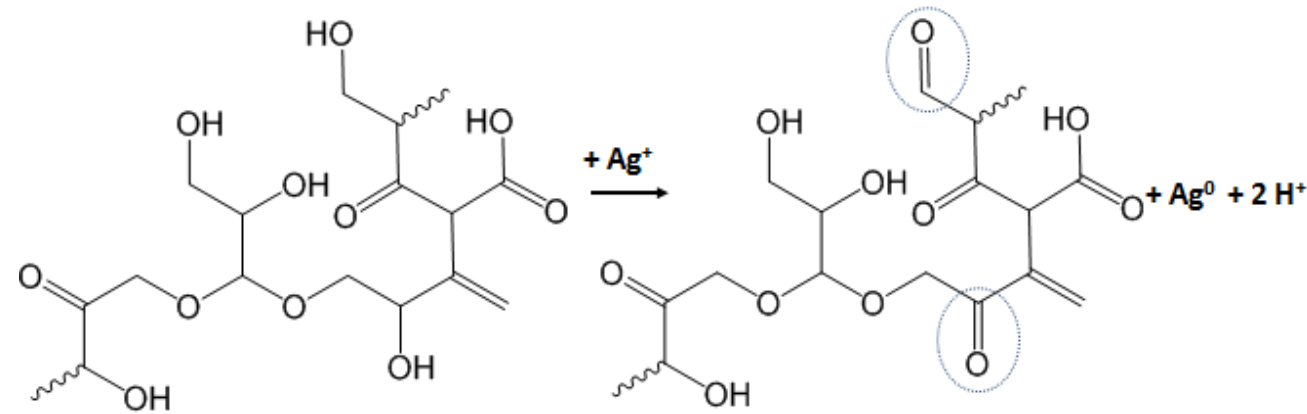<smiles>C=C(C(C(=O)O[Na])C(O)C(C)c1ccccc1)C(C)(O)COC(OCC(O)[C@@H](C)O)C(O)CO</smiles>

Scheme 2. Electrostatic interactions between $\mathrm{Ag}^{+}$and pp-AAl.

\subsection{Repartition and size distribution of silver nanoparticles}

AFM studies are carried out to examine the surface roughness of the different polymers and composite layers. The root mean square roughness values of the surfaces $(\mathrm{Rq})$ are presented in Table 4. $\mathrm{Rq}$ is about $0.3 \pm 0.1$ and $0.9 \pm 0.1 \mathrm{~nm}$ for pp-ANI and pp-AAl respectively, in comparison to about $1.3 \pm 0.1 \mathrm{~nm}$ for $\mathrm{pp}-\mathrm{HDFD}$, indicating that the latter exhibits the highest 
surface roughness, associated with a degradation and aggregation behavior, induced by fluorinated radicals. After silver particles addition, an increase of $\mathrm{Rq}$ for all the polymers is observed. For pp-ANI, Rq increases from 0.3 to $2.8 \pm 0.2 \mathrm{~nm}$, for pp-AAl it increases from 0.9 to $2.9 \pm 0.2 \mathrm{~nm}$, and from 1.3 to $5.3 \pm 0.2 \mathrm{~nm}$ for pp-HDFD. The high quantity of silver particles inserted in pp-ANI compared to pp-AAl, explains the more pronounced increase in Rq. Although the amount of silver inserted in pp-AAl is more important than in the case of ppHDFD, the increase in $\mathrm{Rq}$ is lower. Following these results, $\mathrm{Rq}$ values are then not only attributed to the amount of silver particles but also to their size and which will be studied afterwards.

Table 4. Root mean square roughness values of the different polymer and composite layers.

\begin{tabular}{|c|c|}
\hline Samples & Rq (nm) \\
\hline Bare pp-ANI & $0.3 \pm 0.1$ \\
\hline pp-ANI after impregnation+reduction & $2.8 \pm 0.2$ \\
\hline Bare pp-AAl & $0.9 \pm 0.1$ \\
\hline pp-AAl after impregnation+reduction & $2.9 \pm 0.2$ \\
\hline Bare pp-HDFD & $1.3 \pm 0.1$ \\
\hline pp-HDFD after impregnation+reduction & $5.3 \pm 0.2$ \\
\hline
\end{tabular}

The samples were investigated by transmission electron microscopy (TEM) to visualize the size and shape of silver particles. Spherical nanoparticles of $7.4 \pm 0.4 \mathrm{~nm}$ and $12 \pm 1.2 \mathrm{~nm}$ mean diameter are obtained for pp-AAl and pp-ANI as matrices, respectively (Figure 5). The smallest metal inclusions with the narrowest size distribution are produced by using pp-AAl (Figure 5$\mathrm{b}, \mathrm{h})$. Moreover, for pp-HDFD, the weak chemical affinity between silver and the fluorocarbon film contributes to aggregate silver nanoparticles, inducing a broader size distribution in the range of 6 to $40 \mathrm{~nm}$ (Figure 5-c,i). ${ }^{55,56}$ Accordingly, we can say that silver nanoparticles likely 
prefer to interact with each other rather than with the pp-HDFD matrix, thus the Rq value obtained for the fluorinated composite is well related to the aggregation of silver particles.

The electron diffraction pattern coupled to TEM makes it possible to study the structure of the crystallized materials. The SAED patterns (Figure 5-d,e,f) reveal that the diffraction rings from inner to outer, with $d$-spacings of 2.4, 2, 1.4, and $1.2 \AA$ could be indexed as (111), (200), (220), and (311) reflections, respectively, corresponding to face-centered cubic silver structure (fcc). These values are consistent with diffraction data of fcc silver metal. These results confirm the crystallinity of silver nanoparticles with typical crystalline dots, in contrast to the amorphous structure of polymers.

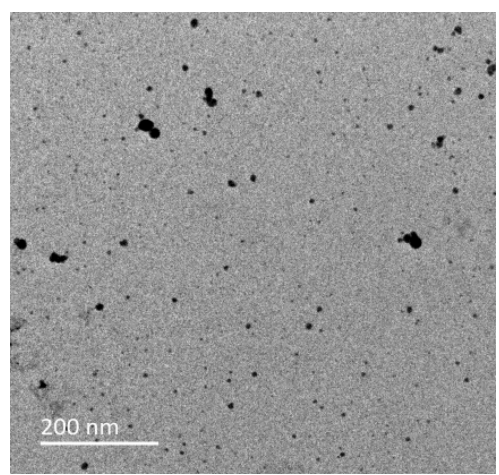

a

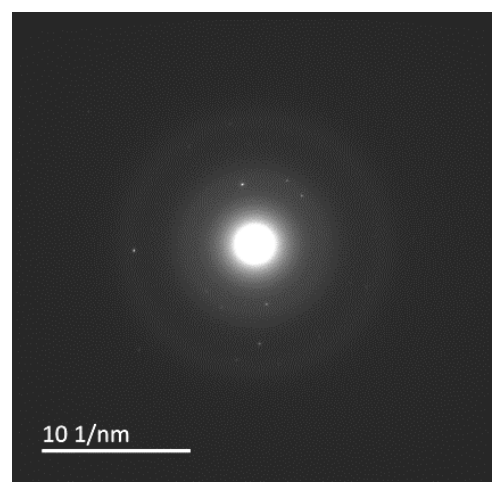

d

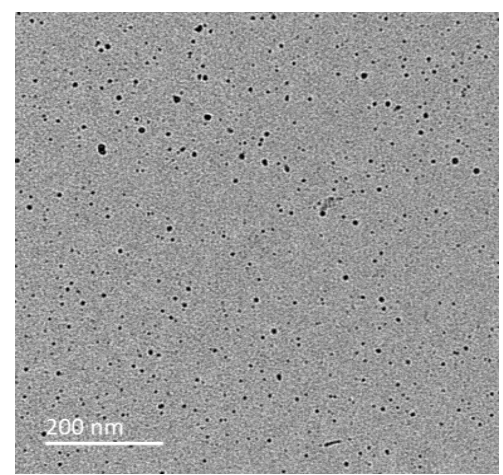

$\mathrm{b}$

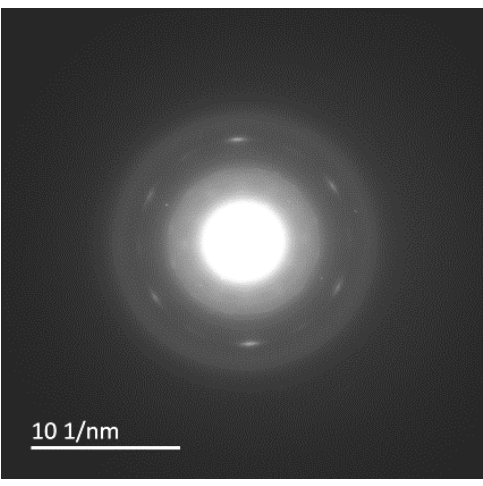

$\mathrm{e}$

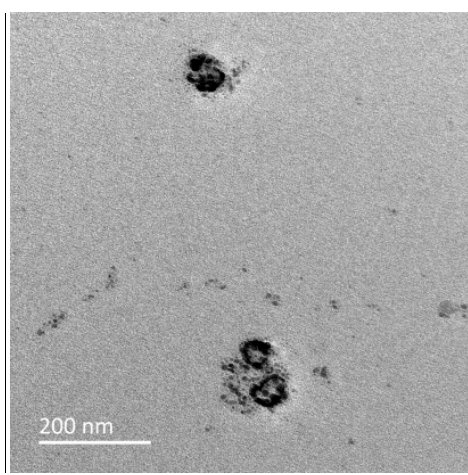

c

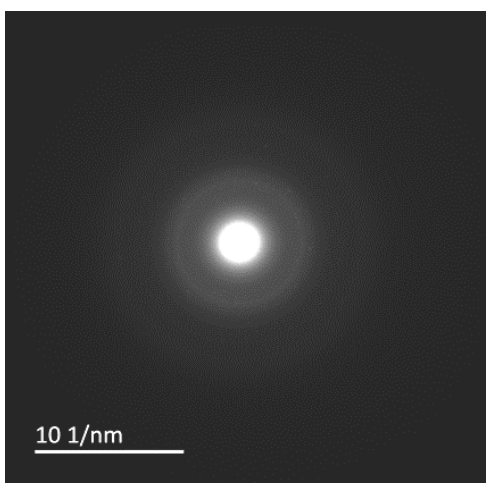

f 


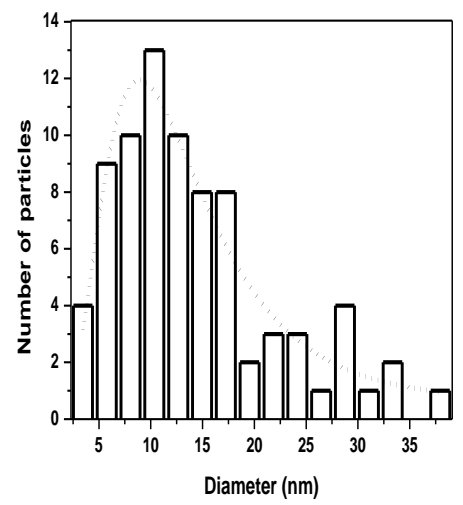

g

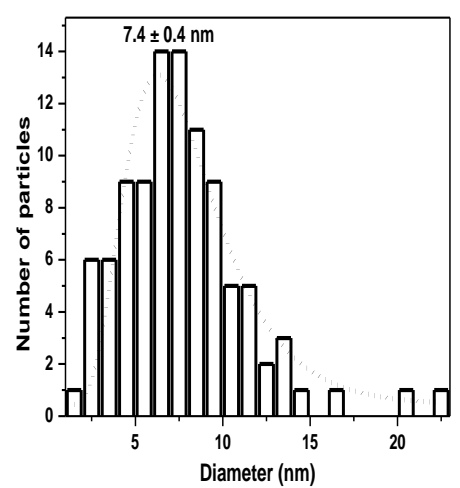

$\mathrm{h}$

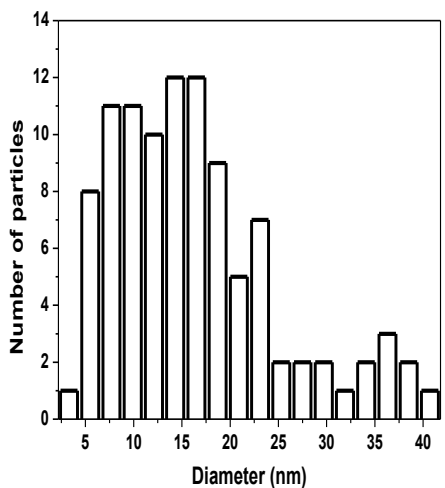

i

Figure 5. TEM images, SAED pattern and Ag particle size distribution in (a,d,g) pp-ANI, (b,e,h) pp-AAl, and (c,f,i) pp-HDFD after impregnation+reduction.

To confirm the formation of AgNPs, UV-Vis absorption spectroscopy has been demonstrated to be an effective tool, which depends on the Surface Plasmon Resonance (SPR). ${ }^{12,14,57,58}$ Figure 6 shows the UV-Visible absorbance spectra of plasma polymers before and after incorporation of AgNPs. pp-ANI shows one peak at $260 \mathrm{~nm}$ assigned to $\pi-\pi^{*}$ transition of benzene rings with a shoulder at $290 \mathrm{~nm}$ assigned to polaron- $\pi *{ }^{*}{ }^{35,59}$ pp-AAl shows a peak at $253 \mathrm{~nm}$ assigned to $\mathrm{C}-\mathrm{O}, \mathrm{C}=\mathrm{O}, \mathrm{C}=\mathrm{C},{ }^{13}$ and for pp-HDFD, a peak at $251 \mathrm{~nm}$ attributed to $\mathrm{CF}, \mathrm{CF}_{2}$ is observed. ${ }^{60,61}$ Previous studies have shown that spherical AgNPs contribute to the absorption band at around $400 \mathrm{~nm}$ in the UV-visible spectra. ${ }^{62-64}$ A SPR band characteristic of AgNPs is detected around $426 \pm 5 \mathrm{~nm}$ for $\mathrm{pp}-\mathrm{ANi}$, and pp-AAl after impregnation, confirming the formation of spherical AgNPs in the plasma polymer matrices. However, after reduction, a slight increase in the peak intensity is observed in the case of pp-ANI, in contrast to pp-AAl, where the peak position, shape and intensity are changed. Taking into account that the peak position is very dependent on the nanoparticle size,${ }^{65,66}$ the nanoparticles in pp-AAl (SPR band at $399 \mathrm{~nm}$ ) are then smaller than those in pp-ANI (SPR band at $423 \mathrm{~nm}$ ), and the size distribution is narrower, due to the narrower shape of the peak, thus supporting the results obtained by TEM. However, in the case of pp-HDFD, the absence of a characteristic peak of silver nanoparticles in the range of 400- 
$430 \mathrm{~nm}$, confirms the formation of larger silver particles that tend to agglomerate, ${ }^{57}$ in addition to the low incorporated amount $(0.1 \%)$. All these observations show the effect of the nature of the polymer matrix on the size and particle size distribution of AgNPs.

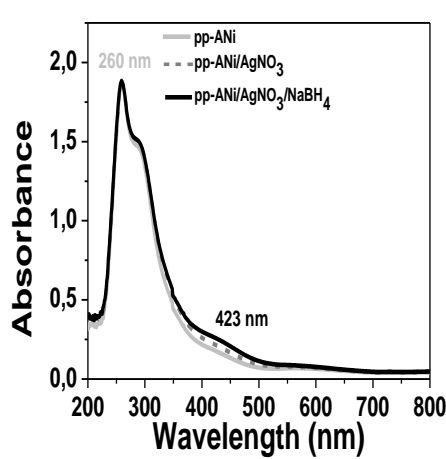

(a)

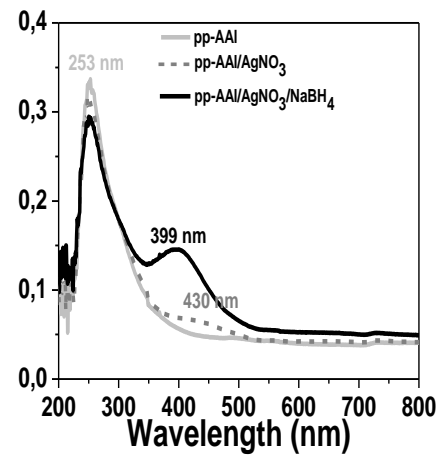

(b)

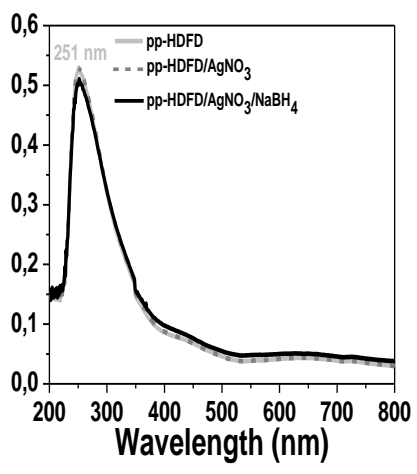

(c)

Figure 6. UV-Vis spectra of (a) pp-ANI, (b) pp-AAl, and (c) pp-HDFD after impregnation+reduction.

In conclusion, the results obtained by AFM and TEM are in good agreement with the results of UV-Vis absorption measurements. A uniform size distribution of AgNPs (narrower plasmon band) and smallest particle size of $7.4 \pm 0.4 \mathrm{~nm}$ (SPR wavelength centered at $399 \mathrm{~nm}$ ) are obtained by using pp-AAl as matrix. In contrast, the fluorocarbon film (pp-HDFD) exhibits particular behavior, where a low affinity for silver is observed with a tendency to aggregate.

\subsection{Gas sensing properties}

In this part, we will show how the sensitivity to ammonia detection is improved when silver nanoparticles are inserted into pp-ANI matrix.

pp-ANI must be doped in order to create gas absorption sites, which are the positively charged nitrogen groups (including polarons). The doped form $\left(\mathrm{pp}-\mathrm{ANI}-\mathrm{H}^{+}\right)$is obtained by oxidative or acidic doping. In this work, the oxidative doping by iodine is used for bare pp-ANI and pp- 
ANI/AgNPs composite to create more absorption sites, ${ }^{19,20}$ taking into account that pp-ANI already shows the presence of some absorption sites $-\stackrel{+}{\mathrm{NH}}$ - as analyzed by XPS (Table 2 ).

The interaction of ammonia gas with doped polyaniline corresponds to the deprotonation (dedoping) of the polymer and can be schematically expressed by the following equation: ${ }^{20,67,68}$ pp-ANI-H ${ }^{+}+\mathrm{NH}_{3} \rightleftarrows$ pp-ANI $+\mathrm{NH}_{4}^{+}$

The wavelength of $430 \mathrm{~nm}$ has been chosen to analyze the absorbance variation after ammonia absorption since it corresponds to a polarons absorption band of $\mathrm{I}_{2}$-doped pp-ANI. The sensitivity of the layers containing or not AgNPs as a function of ammonia concentration is illustrated in Figure 7. The layers' sensitivity increases in a non-linear way when the ammonia concentration increases and tends to reach a plateau. This behaviour is explained by the saturation of the absorption sites at a certain ammonia concentration. Nevertheless, the ammonia vapour-sensing response of the layer with AgNPs is found to be higher than that without AgNPs, for all ammonia concentrations. The introduction of metal nanoparticles onto the polymer matrix is then effective in promoting the sensing response to ammonia. In order to explain the above observations, the chemical and morphological structures of these sensing layers are studied as follows. 


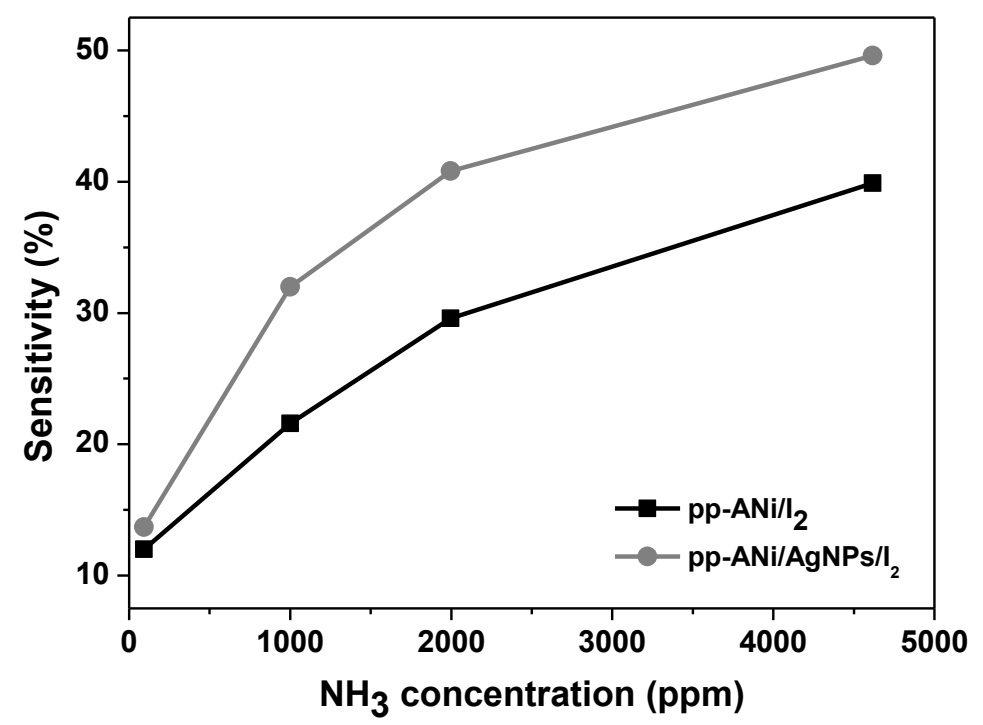

Figure 7. Sensitivity of doped pp-ANI and doped pp-ANI/AgNPs composite as a function of ammonia concentration.

On the one hand, the N1s XPS spectra (Table 2) show higher absorption sites ( $\stackrel{+}{\mathrm{NH}}$ - at 400.6 $\mathrm{eV}$ ) for pp-ANI containing AgNPs (thanks to $\mathrm{Ag}^{+}$oxidative doping agents) than for bare ppANI, thus inducing in the end a better sensitivity. This increase in absorption sites is also observed by UV-Vis spectroscopy, where the shoulder at $290 \mathrm{~nm}$ assigned to polaron- $\pi^{*}$ increases after adding AgNPs (Figure 6-a).

On the other hand, I/N XPS atomic ratio obtained after $24 \mathrm{~h}$ of $\mathrm{I}_{2}$ doping, shows a higher value for pp-ANI containing AgNPs (0.6 \pm 0.06$)$ than for bare pp-ANI $(0.5 \pm 0.05)$, which means that the presence of AgNPs seems to provide a better interaction between pp-ANI and $\mathrm{I}_{2}$. Moreover it is worth to note that the morphological structure of these sensitive layers cannot be neglected. A rougher doped pp-ANI/AgNPs layer $(\mathrm{Rq}=5.8 \pm 0.2 \mathrm{~nm})$ is obtained compared to doped ppANI $(\mathrm{Rq}=0.5 \pm 0.1 \mathrm{~nm})$ (Figure 8$)$. Thus, the presence of AgNPs leads to a higher surface-tovolume ratio that facilitates the diffusion of doping agents and ammonia molecules inside ppANi, hence facilitating their interactions. ${ }^{68,69}$ 


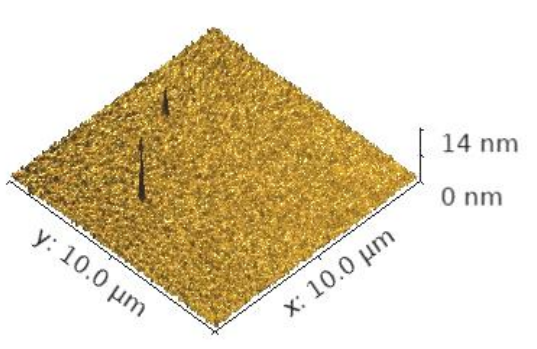

(a)

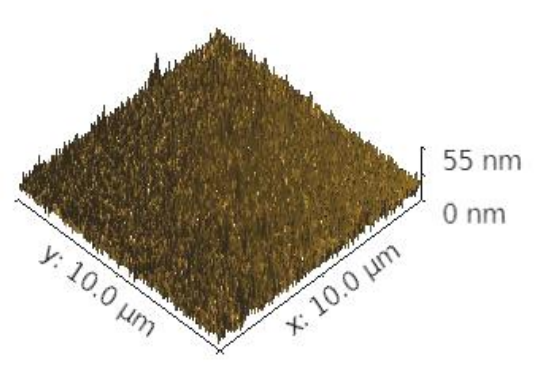

(b)

Figure 8. AFM images of (a) bare doped pp-ANI, and (b) doped pp-ANI/AgNPs composites.

\section{Conclusion}

To summarize, we succeeded in the formation of silver nanoparticles in the different plasma polymer layers but in different amounts and distribution according to the plasma polymer. pp$\mathrm{AAl}$ is the most suitable matrix for the formation of the smallest particle size and the narrowest particle size distribution. But in terms of silver amount, pp-ANI with amine functions shows a pronounced affinity towards AgNPs, in comparison to the other polymer matrices explained by the structure of pp-ANI rich in $\pi$ electrons, as well as the lower electronegativity of $\mathrm{N}$ atom compared to $\mathrm{O}$ and $\mathrm{F}$ ones. We have also demonstrated that AgNPs inserted into pp-ANI result in the improvement of sensitivity towards $\mathrm{NH}_{3}$, due to a change in the chemical and morphological structure of the polymer after adding AgNPs.

\section{Conflict of Interest}

The authors declare that they have no conflict of interest.

\section{References}

1. A. L. Stepanov, S. N. Abdullin, Y. V. Petukhov, Y. N. Osin, R. I. Khaibullin, I. B. 
Khaibullin, Formation of metal-polymer composites by ion implantation, Philosophical Magazine B 80 (2000) 23-28.

2. G. V. Ramesh, S. Porel, T. P. Radhakrishnan, Polymer thin films embedded with in situ grown metal nanoparticles, Chem. Soc. Rev. 38 (2009) 2646-2656.

3. Q. Chen, M. Zhou, Y. Fu, J. Weng, Y. Zhang, L. Yue, F. Xie, C. Huo, Magnetron sputtering synthesis silver and organic PEO nanocomposite, Surf. Coatings Technol. 202 (2008) 5576-5578.

4. K. Gupta, P. C. Jana, A. K. Meikap, Optical and electrical transport properties of polyaniline-silver nanocomposite, Synth. Met. 160 (2010) 1566-1573.

5. J. Shan, Z. Ma, A review on amperometric immunoassays for tumor markers based on the use of hybrid materials consisting of conducting polymers and noble metal nanomaterials, Microchim. Acta 184 (2017) 969-979.

6. S. Prakash, T. Chakrabarty, A. K. Singh, V. K. Shahi, Polymer thin films embedded with metal nanoparticles for electrochemical biosensors applications, Biosens. Bioelectron. 41 (2013) 43-53.

7. M. Trchová, J. Stejskal, The reduction of silver nitrate to metallic silver inside polyaniline nanotubes and on oligoaniline microspheres, Synth. Met. 160 (13-14) (2010) $1479-1486$.

8. P. Xu, X. Han, B. Zhang, N. H. Mack, S. H. Jeon, H. L. Wang, Synthesis and characterization of nanostructured polypyrroles: Morphology-dependent electrochemical responses and chemical deposition of $\mathrm{Au}$ nanoparticles, Polymer (Guildf) 50 (2009) 2624-2629.

9. N. Cioffi, L. Torsi, I. Losito, L. Sabbatini, P. Zambonin, T. Bleve-Zacheo, Nanostructured palladium-polypyrrole composites electrosynthesised from organic solvents, Electrochim. Acta 46 (2001) 4205-4211. 
10. P. Pascariu, A. Airinei, M. Grigoras, L. Vacareanu, F. Iacomi, Metal-polymer nanocomposites based on $\mathrm{Ni}$ nanoparticles and polythiophene obtained by electrochemical method, Appl. Surf. Sci. 352 (2015) 95-102.

11. K. Vasilev, V. Sah, K. Anselme, C. Ndi, M. Mateescu, B. Dollmann, P. Martinek, H. Ys, L. Ploux, H. J. Griesser, Tunable antibacterial coatings that support mammalian cell growth, Nano Lett. 10 (2010) 202-207.

12. V. Kumar, C. Jolivalt, J. Pulpytel, R. Jafari, F. Arefi-Khonsari, Development of silver nanoparticle loaded antibacterial polymer mesh using plasma polymerization process, $\mathrm{J}$. Biomed. Mater. Res. A 101 (2013) 1121-1132.

13. A. Fahmy, J. Friedrich, F. Poncin-Epaillard, D. Debarnot, Plasma polymerized allyl alcohol/ $\mathrm{O}_{2}$ thin films embedded with silver nanoparticles, Thin Solid Films 616 (2016) $339-347$.

14. A. Airoudj, L. Ploux, V. Roucoules, Effect of plasma duty cycle on silver nanoparticles loading of cotton fabrics for durable antibacterial properties, J. Appl. Polym. Sci. 132 (2015).

15. E. Kosenko, Y. Kaminsky, E. Grau, M. D. Miñana, S. Grisolía, V. Felipo, Nitroarginine, an inhibitor of nitric oxide synthetase, attenuates ammonia toxicity and ammoniainduced alterations in brain metabolism, Neurochem. Res. 20 (1995) 451-456.

16. G. Sarala Devi, V. Bala Subrahmanyam, S. C. Gadkari, S. K. Gupta, $\mathrm{NH}_{3}$ gas sensing properties of nanocrystalline $\mathrm{ZnO}$ based thick films, Anal. Chim. Acta 568 (2006) 4146.

17. Q. Chang, K. Zhao, X. Chen, M. Li, J. Liu, Preparation of gold/polyaniline/multiwall carbon nanotube nanocomposites and application in ammonia gas detection, J. Mater. Sci. 43 (2008) 5861-5866.

18. A. Joshi, S. A. Gangal, S. K. Gupta, Ammonia sensing properties of polypyrrole thin 
films at room temperature, Sensors Actuators, B Chem. 156 (2011) 938-942.

19. A. Airoudj, D. Debarnot, B. Bêche, F. Poncin-Epaillard, Development of an optical ammonia sensor based on polyaniline/epoxy resin (SU-8) composite, Talanta 77 (2009) $1590-1596$.

20. T. Mérian, D. Debarnot, V. Rouessac, F. Poncin-Epaillard, Ammonia absorption study of pulsed-plasma polyaniline by quartz crystal microgravimetry and UV/vis spectrometry, Talanta 81 (2010) 602-608.

21. X. Ma, G. Li, H. Xu, M. Wang, H. Chen, Preparation of polythiophene composite film by in situ polymerization at room temperature and its gas response studies, Thin Solid Films 515 (2006) 2700-2704.

22. S. Cui, H. Pu, G. Lu, Z. Wen, E. C. Mattson, C. Hirschmugl, M. GajdardziskaJosifovska, M. Weinert, J. Chen, Fast and selective room-temperature ammonia sensors using silver nanocrystal-functionalized carbon nanotubes, ACS Appl. Mater. Interfaces 4 (2012) 4898-4904.

23. X. Yang, L. Li, F. Yan, Polypyrrole/silver composite nanotubes for gas sensors, Sensors Actuators, B Chem. 145 (2010) 495-500.

24. U. V. Patil, N. S. Ramgir, N. Karmakar, A. Bhogale, A. K. Debnath, D. K. Aswal, S. K. Gupta, D. C. Kothari, Room temperature ammonia sensor based on copper nanoparticle intercalated polyaniline nanocomposite thin films, Appl. Surf. Sci. 339 (2015) 69-74.

25. T. Sen, N. G. Shimpi, S. Mishra, R. Sharma, Polyaniline $/ \gamma-\mathrm{Fe}_{2} \mathrm{O}_{3}$ nanocomposite for room temperature LPG sensing, Sensors Actuators, B Chem. 190 (2014) 120-126.

26. E. Detsria, J. Popanyasak, Fabrication of silver nanoparticles/polyaniline composite thin films using Layer-by-Layer self-assembly technique for ammonia sensing, Colloids and Surfaces A: Physicochem. Eng. Aspects 467 (2015) 57-65. 
27. A.A. Athawale, P.P. Katre, Ag dispersed conducting polyaniline nanocomposite as a selective sensor for ammonia, J. Metastable Nanocrystalline Mater. 23 (2005) 323-326.

28. X. Li, Y. Gao, J. Gong, L. Zhang, L. Qu, Polyaniline/Ag composite nanotubes prepared through UV rays irradiation via fiber template approach and their $\mathrm{NH}_{3}$ gas sensitivity, J. Phys. Chem. C 113 (2008) 69-73.

29. A. Mansour, F. Poncin-Epaillard, D. Debarnot, Distribution of metal nanoparticles in a plasma polymer matrix according to the structure of the polymer and the nature of the metal, Thin Solid Films, https://doi.org/10.1016/j.tsf.2019.04.036.

30. T. R. Gengenbach, Z. R. Vasic, S. Li, R. C. Chatelier, H. J. Griesser, Contributions of restructuring and oxidation to the aging of the surface of plasma polymers containing heteroatoms, Plasmas Polym. 2 (1997) 91-114.

31. X. Gong, L. Dai, A. W. H. Mau, H. J. Griesser, Plasma-polymerized polyaniline films: Synthesis and characterization, J. Polym. Sci. Part A Polym. Chem. 36 (1998) 633-643.

32. R. Hernandez, A. F. Diaz, R. Waltman, J. Bargon, Surface characteristics of thin films prepared by plasma and electrochemical polymerizations, J. Phys. Chem. 88 (1984) $3333-3337$.

33. P. A. F. Herbert, L. O’Neill, J. Jaroszýnska-Wolínska, Soft Plasma polymerization of gas state precursors from an atmospheric pressure corona plasma discharge, Chem. Mater. 21 (2009) 4401-4407.

34. P. A. F. Herbert, L. O’Neill, J. Jaroszyńska-Wolińska, C. P. Stallard, A. Ramamoorthy, D. P. Dowling, A comparison between gas and atomized liquid precursor states in the deposition of functional coatings by pin corona plasma, Plasma Process. Polym. 8 (2011) $230-238$.

35. D. Debarnot, T. Mérian, F. Poncin-Epaillard, Film Chemistry Control and Growth Kinetics of Pulsed Plasma-Polymerized Aniline, Plasma Chem. Plasma Process. 31 
(2011) 217-231.

36. A. Fahmy, R. Mix, A. Schönhals, J. F. Friedrich, Structure-Property Relationship of Thin Plasma Deposited Poly(allyl alcohol) Films, Plasma Chem. Plasma Process. 31 (2011) 477-498.

37. H. Yasuda, M. O. Bumgarner, J. J. Hillman, Polymerization of organic compounds in an electrodeless glow discharge. V. Amines and nitriles, J. Appl. Polym. Sci. 19 (1975) 1403-1408.

38. I. Medina-Ramirez, S. Bashir, Z. Luo, J. L. Liu, Green synthesis and characterization of polymer-stabilized silver nanoparticles, Colloids Surfaces B Biointerfaces 73 (2009) $185-191$.

39. X. Li, A. Rafie, Y. Y. Smolin, S. Simotwo, V. Kalra, K. K. S. Lau, Engineering conformal nanoporous polyaniline via oxidative chemical vapor deposition and its potential application in supercapacitors, Chem. Eng. Sci. (2018) DOI: $\underline{10.1016 / j . c e s .2018 .06 .053}$.

40. M. M. Mahat, D. Mawad, G. W. Nelson, S. Fearn, R. G. Palgrave, D. J. Payne, M. M. Stevens, Elucidating the deprotonation of polyaniline films by X-ray photoelectron spectroscopy, J. Mater. Chem. C 3 (2015) 7180-7186.

41. Z. F. Li, E. T. Kang, K. G. Neoh, K. L. Tan, Effect of thermal processing conditions on the intrinsic oxidation states and mechanical properties of polyaniline films, Synth. Met. 87 (1997) 45-52.

42. S. Kumar, F. Gaillard, G. Bouyssoux, A. Sartre, High-resolution XPS studies of electrochemically synthesized conducting polyaniline films, Synth. Met. 36 (1990) 111127.

43. P. Xu, X. Han, B. Zhang, Y. Du, H.-L. Wang, Multifunctional polymer-metal nanocomposites via direct chemical reduction by conjugated polymers, Chem. Soc. Rev. 
43 (2014) 1349-1360.

44. T. Zhao, R. Sun, S. Yu, Z. Zhang, L. Zhou, H. Huang, R. Du, Size-controlled preparation of silver nanoparticles by a modified polyol method, Colloids Surfaces A Physicochem. Eng. Asp. 366 (2010) 197-202.

45. N. V. Blinova, J. Stejskal, M. Trchová, I. Sapurina, G. Ćirić-Marjanović, The oxidation of aniline with silver nitrate to polyaniline-silver composites, Polymer (Guildf) 50 (2009) $50-56$.

46. R. Zeng, M. Z. Rong, M. Q. Zhang, H. C. Liang, H. M. Zeng, Interfacial interaction in Ag/polymer nanocomposite films, J. Mater. Sci. Lett. 20 (2001) 1473-1476.

47. T. Yonezawa, N. Toshima, Mechanistic consideration of formation of polymer-protected nanoscopic bimetallic clusters, J. Chem. Soc. Faraday Trans. 91 (1995) 4111.

48. G. Nesher, G. Marom, D. Avnir, Metal-polymer composites: Synthesis and characterization of polyaniline and other polymer@silver compositions, Chem. Mater. 20 (2008) 4425-4432.

49. X. G. Li, M. R. Huang, S. X. Li, Facile synthesis of poly(1,8-diaminonaphthalene) microparticles with a very high silver-ion adsorbability by a chemical oxidative polymerization, Acta Mater. 52 (2004) 5363-5374.

50. Y. Wang, Q. Yang, G. Shan, C. Wang, J. Du, S. Wang, Y. Li, X. Chen, X. Jing, Y. Wei, Preparation of silver nanoparticles dispersed in polyacrylonitrile nanofiber film spun by electrospinning, Mater. Lett. 59 (2005) 3046-3049.

51. Y. Sun, Y. Xia, Large-scale synthesis of uniform silver nanowires through a soft, selfseeding, polyol process, Adv. Mater. 14 (2002) 833-837.

52. S. Ahrland, J. Chatt, N. R. Davies, The relative affinities of ligand atoms for acceptor molecules and ions, Q. Rev. Chem. Soc. 12 (1958) 265-276.

53. H. Wang, X. Qiao, J. Chen, X. Wang, S. Ding, Mechanisms of PVP in the preparation 
of silver nanoparticles, Mater. Chem. Phys. 94 (2005) 449-453.

54. F. J. Liu, L. M. Huang, T. C. Wen, A. Gopalan, J. S. Hung, Interfacial synthesis of platinum loaded polyaniline nanowires in poly(styrene sulfonic acid), Mater. Lett. 61 (2007) 4400-4405.

55. X. Wang, J. Zuo, P. Keil, G. Grundmeier, Comparing the growth of PVD silver nanoparticles on ultra thin fluorocarbon plasma polymer films and self-assembled fluoroalkyl silane monolayers, Nanotechnology 18 (2007) 265-303.

56. V. Mankad, R. K. Kumar, P. K. Jha, Investigation of blue-shifted plasmon resonance: An optical properties study of silver nanoparticles, Nanosci. Nanotechnol. Lett. 5 (2013) 889-894.

57. N. T. Nguyen, J. H. Liu, A green method for in situ synthesis of poly(vinyl alcohol)/chitosan hydrogel thin films with entrapped silver nanoparticles, J. Taiwan Inst. Chem. Eng. 45 (2014) 2827-2833.

58. S. Ashraf, A. Z. Abbasi, C. Pfeiffer, S. Z. Hussain, Z. M. Khalid, P. R. Gil, W. J. Parak, I. Hussain, Protein-mediated synthesis, $\mathrm{pH}$-induced reversible agglomeration, toxicity and cellular interaction of silver nanoparticles, Colloids Surfaces B Biointerfaces 102 (2013) 511-518.

59. Q. Huang, G. Chen, J. Liu, One-pot synthesis of polyaniline doped with transition metal ions using $\mathrm{H}_{2} \mathrm{O}_{2}$ as oxidant, Polym. Adv. Technol. (2014) 1391-1395.

60. F. Fanelli, Optical emission spectroscopy of argon-fluorocarbon-oxygen fed atmospheric pressure dielectric barrier discharges, Plasma Process. Polym. 6 (2009) 547-554.

61. I. Vinogradov, A. Lunk, Spectroscopic diagnostics of DBD in Ar/fluorocarbon mixtures - Correlation between plasma parameters and properties of deposited polymer films, Plasma Process. Polym. 2 (2005) 201-208.

62. K. Shameli, M. Bin Ahmad, S. D. Jazayeri, S. Sedaghat, P. Shabanzadeh, H. Jahangirian, 
M. Mahdavi, Y. Abdollahi, Synthesis and characterization of polyethylene glycol mediated silver nanoparticles by the green method, Int. J. Mol. Sci. 13 (2012) 66396650.

63. Y. Sun, Y. Xia, Gold and silver nanoparticles: A class of chromophores with colors tunable in the range from 400 to $750 \mathrm{~nm}$, Analyst 128 (2003) 686-691.

64. K. Stamplecoskie, J. Scaiano, Light Emitting Diode Irradiation Can Control the Morphology and Optical Properties of Silver Nanoparticles, J. Am. Chem. Soc. 132(6) (2010) 1825-1827.

65. L. Balan, R. Schneider, D. J. Lougnot, A new and convenient route to polyacrylate/silver nanocomposites by light-induced cross-linking polymerization, Prog. Org. Coatings 62 (2008) 351-357.

66. G. A. Martinez-Castanon, N. Niño-Martínez, F. Martínez-Gutierrez, J. R. MartínezMendoza, F. Ruiz, Synthesis and antibacterial activity of silver nanoparticles with different sizes, J. Nanoparticle Res. 10 (2008) 1343-1348.

67. H. T. Hien, H. T. Giang, N. Van Hieu, T. Trung, C. Van Tuan, Elaboration of Pdnanoparticle decorated polyaniline films for room temperature $\mathrm{NH}_{3}$ gas sensors, Sensors Actuators, B Chem. 249 (2017) 348-356.

68. S. Mikhaylov, N. Ogurtsov, Y. Noskov, N. Redon, P. Coddeville, J. L. Wojkiewicz, A. Pud, Ammonia/amine electronic gas sensors based on hybrid polyaniline- $\mathrm{TiO}_{2}$ nanocomposites. the effects of titania and the surface active doping acid, RSC Adv. 5 (2015) 20218-20226.

69. S. Virji, J. Huang, R. B. Kaner, B. H. Weiler, Polyaniline nanofiber gas sensor: examination of response mechanisms, Nano Lett. 4 (2004) 491-496. 